\title{
Non-linear explosion tremor at Sangay, Volcano, Ecuador
}

\author{
Jonathan M. Lees ${ }^{\mathrm{a}, *}$, Mario Ruiz \\ ${ }^{a}$ University of North Carolina, Department of Geological Sciences, CB\#3315, Mitchell Hall, Chapel Hill, NC 27599-3315, United States
}

Received 1 February 2007; accepted 6 August 2007

\begin{abstract}
A detailed analysis of discrete degassing pulses, chugs, at Sangay volcano, was performed on seismic and infrasonic records to determine the physics of the conduit. Infrasonic chugging signals appear as repetitive pulses with small variations in amplitude and time lag. An automated time-domain analysis was developed to measure with high precision time intervals and amplitudes at different wave arrivals, reducing the possibility error associated with hand picking. Using this automated method, a strong positive correlation of acoustic amplitude with repose time between individual pulses on chugging signals of Sangay was found on numerous oscillating sequences. Frequency gliding of apparent harmonic frequencies generally trends from high to low frequency at Sangay, in contrast to trends at Karymsky Volcano, Russia. A new description of chugging events using wavelet transform methods, appropriate for non-stationary signals, shows subtle changes in the waveforms relate to physical processes in the volcano. A system of non-linear feedback, based on choked flow at the vent, is postulated as the most likely source of this volcanic tremor. (C) 2007 Elsevier B.V. All rights reserved.
\end{abstract}

Keywords: volcanoes; explosions; Strombolian activity; infrasound; seismo-acoustic; non-linear; wavelet transform; harmonic tremor; quasi-periodic

\section{Introduction}

Volcanic "chugging", a specialized tremor observed at several exploding volcanoes, is currently being used to understand the physics and structure of volcanic conduits during low level Strombolian style activity. Chugging has been identified most clearly at Arenal Volcano, Costa Rica, (Benoit and McNutt, 1997; Garces et al., 1998; Hagerty et al., 2000), and Karymsky Volcano, Kamchatka, (Johnson et al., 1998; Johnson and Lees, 2000; Lees et al., 2004) as a sequence of puffing or explosions following an initial explosion which apparently triggers

\footnotetext{
* Corresponding author. Tel.: +1 919962 0695; fax: +1 919 .

E-mail address: jonathan.lees@unc.edu (J.M. Lees).

URL: http://www.unc.edu/ leesj (J.M. Lees).
}

the sequence. The quasi-periodic chugging sequence 31 consistently exhibits an inter-pulse period varying from 32 $0.7-2 \mathrm{~s}$ and produces a series of pulses in the infrasonic 33 frequency band. Chugging sequences are not restricted 34 to the low frequency bands and can often be heard in 35 audible frequency ranges, although we know of no 36 documented cases of researchers visually observing gas 37 or other emissions associated directly with chugging. 38 This maybe due to the fact that chugging usually follows 39 a larger Strombolian style explosion and pulsations 40 that occur in the aftermath are obstructed by the larger 41 amounts of gas and ash remaining from the initial blast. 42 The individual infrasonic chugging signals appear to be 43 discrete and time limited, often evolving over the length 44 of the chugging sequence. Corresponding seismic sig- 45 nals, distorted because they are convolved with the in- 46 tervening earth structure, display more complex signals 47 
associated with path effect and site response, as well as the source time function of individual tremor pulses. Since the acoustic signals do not suffer significant distortion from path effects, we concentrate primarily on analysis of the infrasonic signals in this study.

From April 21-26, 1998, two portable, broadband, seismic stations including infrasonic microphones were deployed on the southern flanks of Sangay to monitor activity and record infrasonic acoustic waves as well as seismic emission from the vents (Fig. 1). During this survey, 38 chugging signals were recorded on seismic and acoustic stations. Johnson and Lees (2000) provide a detailed description of the 1998 deployment and show that 60 chugging events of Sangay and Karymsky have, in gen- 61 eral, similar waveforms, although differences in occur- 62 rence, duration and spectral content were cited. Prior to the 63 1998 deployment, long-period, hybrid and tremor events 64 (about 5/day) were recorded in 1995 on a short period 65 seismic station $4.3 \mathrm{~km}$ from the summit. The 1995 events 66 exhibited characteristics similar to the 1998 recordings. 67 Some of the 1995 events were associated with audibly and 68 visually observed explosions followed by roar-like, 69 pulsating, rhythmic exhalations (GVN, 1996). Because 70 of the remoteness of Sangay, the volcano is not monitored 71

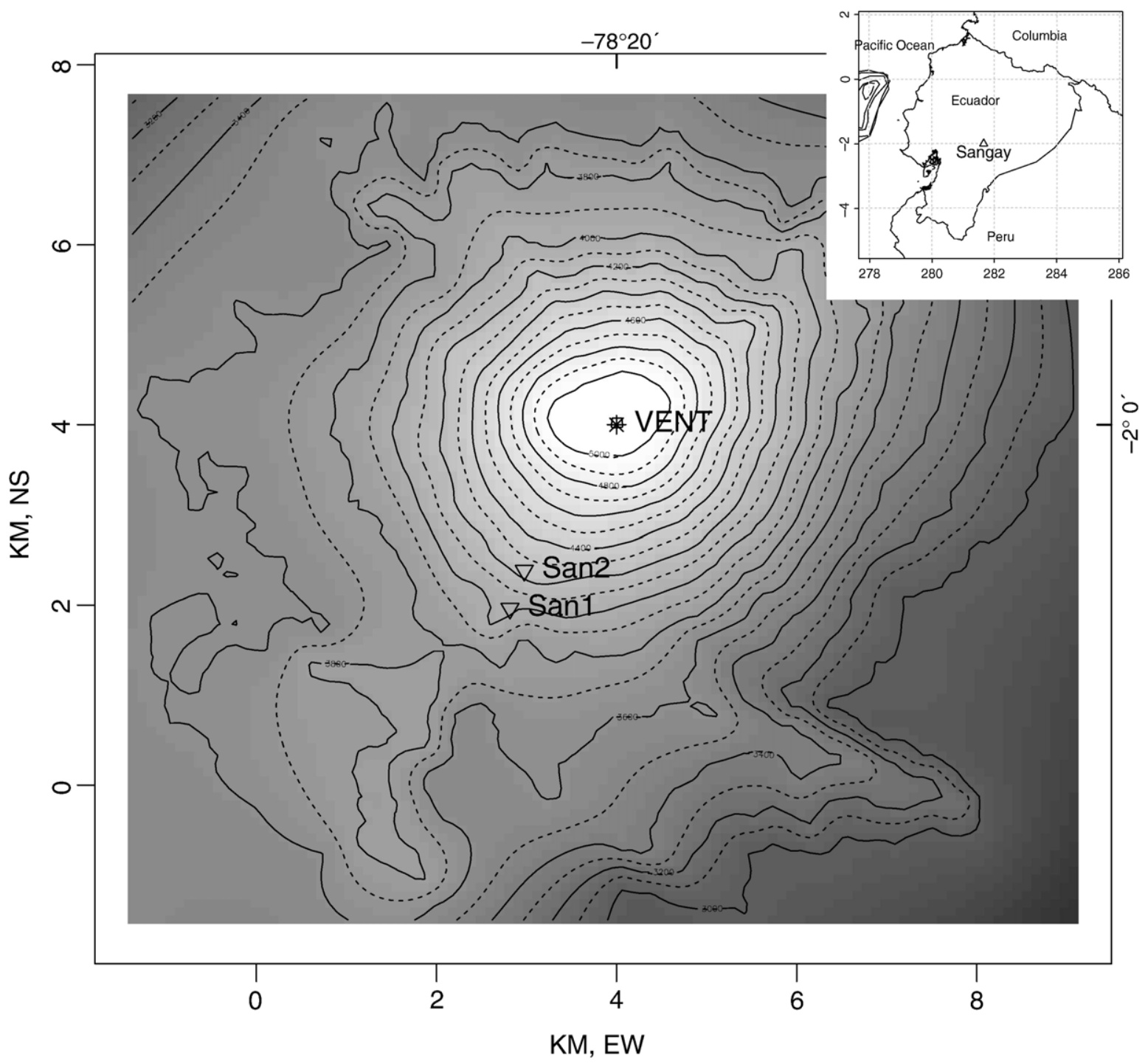

Fig. 1. Topographic map of Sangay showing station location and vent region. Contours are drawn at $200 \mathrm{~m}$ intervals. Stations were located down slope from the active vent. Data presented in this paper are from station San2 $1200 \mathrm{~m}$ from the vent. 
regularly, although we expect this low level activity, including pulsating tremor, is ongoing and persistent.

Sangay is the most active volcano in the Northern Andes. It has been in a state of continuous eruption for as long as historic accounts are available. Large eruptive activity, including high ash columns, has been reported on more than 16 occasions between 1728 and 1980 (J. Egred, pers. comm.). A detailed review of the geology, petrology and descriptions of the volcano can be found in Monzier et al. (1999). Ongoing activity at Sangay consists primarily of low level Strombolian explosions with block and ash explosions, occurring, on average, 1-2 times per hour. In the past few years activity has migrated across the vents at the summit. This paper uses data collected solely from the 1998 deployment.

At Sangay, the summit complex of vents contains several craters with a WSW-ENE trend, although at the time of the field experiment, only a crater at the NE edge was erupting. Time delays between acoustic and seismic arrivals have a mean value of $4.02 \mathrm{~s}(\sigma=0.105 \mathrm{~s})$ at station SAN2, the closest to the vent. Based on the consistency of these time delays, we are confident that the sources studied here are derived from only one of the active vents. Onsets of acoustic and seismic waveforms of explosions recorded at Sangay are remarkably similar despite the emergent nature of seismic signals (Johnson and Lees, 2000). These observations support the hypothesis of repeatable sources at stable locations for this type of event at Sangay.

Of all volcanoes that exhibit "chugging" behavior Sangay and Karymsky share seismo-acoustic characteristics that are more similar to each other than others studied by the authors. It is worthwhile noting that these two volcanoes differ in their size and tectonic setting. Sangay vents are located at $5000 \mathrm{~m}$ elevation as compared to Karymsky's 1600 height. Each volcano is conical in shape, located in a subduction zone setting, although Sangay is situated at the southern terminus of volcanism in the Northern Andes whereas Karymsky is far from potentially disturbing edge effects associated with slab termination. Each volcano exhibits an array of whole rock geochemistry ranging from silicic to mafic character, although for the most both volcanoes are dominated by andesitic eruptions and lava flows (Zobin and Levina, 1998; Monzier et al., 1999; Eichelberger and Izbekov, 2000; Ozerov et al., 2003; Lees et al., 2004).

Analysis in the earlier paper (Johnson and Lees, 2000) used spectrogram analysis of signals to show effects of harmonic tremor and gliding, the time-varying fluctuations of the fundamental mode and harmonics of chugging series. Although Sangay and Karymsky volcanoes share physical similarities in their eruption activity parameters (eruptive scale time, magma viscos- 124 ity, volatile content, and mass flux though the vent) 125 chugging events at each exhibit broad differences in 126 duration, occurrence, and frequency content. In this 127 paper we extend the analyses described earlier and show 128 that activity at Sangay is much more similar to Karymsky 129 behavior than previously understood. Using an auto- 130 matic time-domain analysis of amplitude-time lapse 131 ratios, we show that chugging amplitudes recorded on 132 infrasonic sensors appear to be correlated with time be- 133 tween individual chugs, as observed at Karymsky in 134 1997 (Lees et al., 2004). This observation has important 135 implications for modeling volcanoes in general, regard- 136 ing the interaction of vent and ascending combinations 137 of mixed-phase mass prior to expulsion from the volcano 138 orifice (Ozerov et al., 2003). Our analysis is related to the 139 non-linear analyses of chaotic processes, although in this 140 study we base our conclusions on much more detailed 141 observations of the chugging time series. Finally we 142 present a new description of chugging events using 143 wavelet transforms methods appropriate for non-station- 144 ary signals.

\section{Data analysis}

Eleven episodes of high signal-noise sequences 147 of chugging were isolated at Sangay in the period of 148 observation in 1998. These were extracted from the full 149 data set and analyzed as described below. At least two 150 sequences were complex series known as 'intermittent 151 chugging'(Lees et al., 2004), i.e. sequences that were 152 modulated by a much longer wavelength process, so 153 those were broken down and investigated in parts. For 154 each of the selected episodes, detailed analysis of the 155 time intervals between individual chugs and the am- 156 plitudes of individual chugs was recorded (Fig. 2). To be 157 as consistent as possible, automation of time and ampli- 158 tude determinations was implemented. All time picks 159 were made by selecting the maximum amplitude in a 160 window surrounding each chug signal on the raw 161 acoustic records. This approach eliminated the possibil- 162 ity of bias associated with decision making by an analyst. 163 To provide estimates of the error in the automated picks, 164 we used the following procedure: after arrival times were 165 determined, a small window surrounding the maximum 166 of each chug was selected and low-pass filtered using a 167 Gaussian Nadaraya-Watson kernel regression smoother 168 with central frequencies at 6 and $2 \mathrm{~Hz}$ respectively 169 (R Development Core Team, 2006). The difference 170 between the $2 \mathrm{~Hz}$ filtered maximum arrival-time/ 171 amplitude versus the $6 \mathrm{~Hz}$ arrival-time/amplitude repre- 172 sents an estimate of the quality of the arrival time 173 

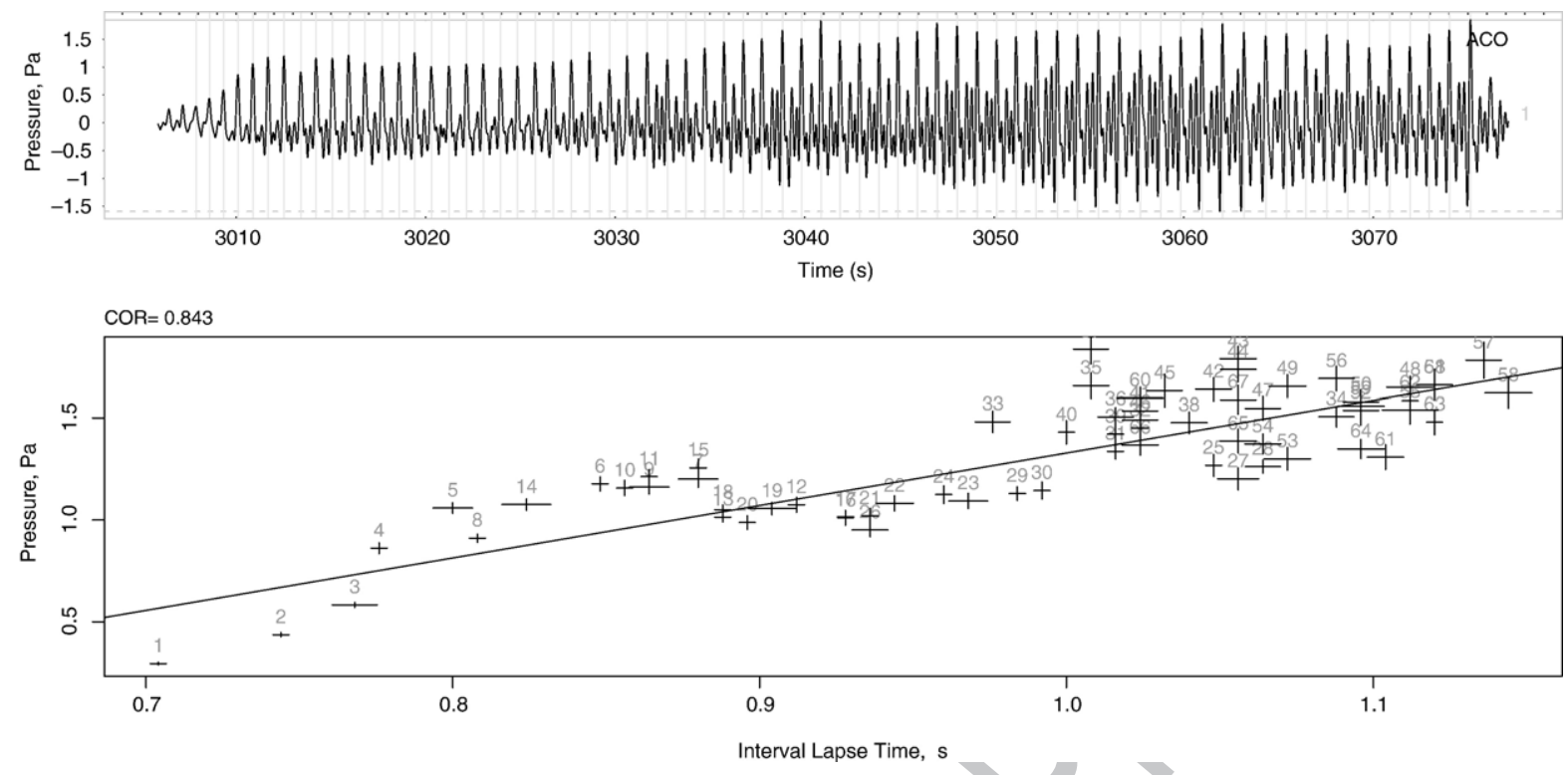

determination (Fig. 3). Uncertainty estimates rely on the choice of smoothing parameters, naturally, so an effort was made to design the filters that increase error bars when the peak region of the chug is multi-modal, or noisy. This method seemed to provide reasonable error bounds in amplitude and time on the individual chugs, with 179 maxima of $4.9 \%$ and $1.7 \%$ error variation, respectively. 180

The advantage of measuring time intervals so pre- 181 cisely over conventional spectrum methods is clear: 182 estimates of frequency spectra generally mix signals over 183

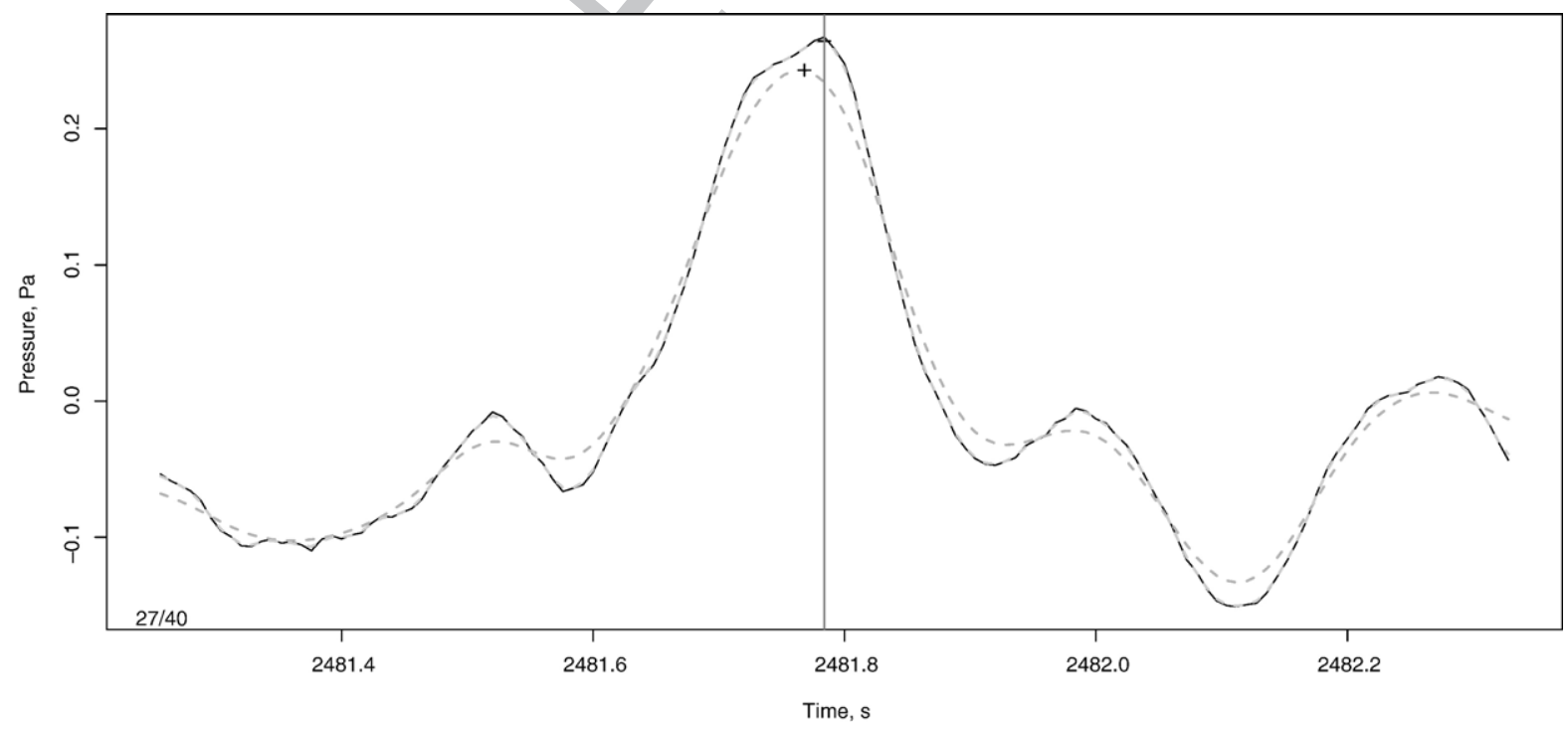

Fig. 3. Example chug illustrating estimates of error in time and amplitude. Arrival times are estimated by the peak amplitude in a short window surrounding the chug pulse. The pulse is smoothed at two different frequencies (dashed, grey lines) and the difference between the amplitude and arrival time of each (plus symbols) provides an automated method to extract the uncertainty of times and amplitudes. Uncertainties are used to weight the linear regression presented in Fig. 2 . 
several wavelengths to extract the frequency-amplitude information (Lees et al., 2004). The time-domain approach taken here preserves details of the structure of the sequence that cannot be obtained using a spectrogram. The apparent relation between amplitude and time interval between chugs is further obscured by inconsistent estimation of the time arrivals, as would be the case if arrivals were determined by eyeball estimation. By developing an automated algorithm to extract this information, the method can be applied to and compared with other datasets with general reliability.

\section{Amplitude-time lapse analysis}

We isolated eleven sequences of chugging activity and applied the automated time-domain analysis described above. Uncertainties in pulse arrival-time and amplitude estimates were used to weight linear regressions between lag (lapse) times and amplitudes. In nearly all the chugging sequences studied, there is a statistically significant positive correlation between amplitude and time interval between chugs (Fig. 4). While this observation is not universal, i.e. there are sequences which do not show a strong correlation, in those instances where chugging is relatively simple, the rule holds. 206 Occasionally chugging sequences are complex, i.e. they 207 are modulated by a longer period envelope that regulates 208 amplitude fluctuations. In these cases, the chugging 209 series were broken down and analyzed individually. The 210 mean slope for sequences which had a statistically 211 positive slope was $2.2 \mathrm{~Pa} / \mathrm{s}$. We note that accurate and 212 stable calibration of the Venema electret microphone 213 sensitivity is not available for data recorded at Sangay in 214 1998 (Johnson et al., 2003). In this paper we used an 215 estimated $30 \mathrm{mV} / \mathrm{Pa}$ to convert volts to pressure. The 216 critical observation here is the positive relation between 217 amplitudes and time lags whereas the absolute value of 218 the slope is of lesser concern.

\section{Frequency gliding}

Frequency gliding occurs when the fundamental and 221 corresponding harmonic frequencies fluctuate in time 222 (Benoit and McNutt, 1997; Garces et al., 1998; Hagerty 223 et al., 2000; Lees et al., 2004). At Langila volcano tremor 224 related to puffing sounds of emissions exhibited frequen- 225 cy variations greater than $50 \%$ over a time span of about 226 1 min (Mori et al., 1989). The tremor at Langila had an 227

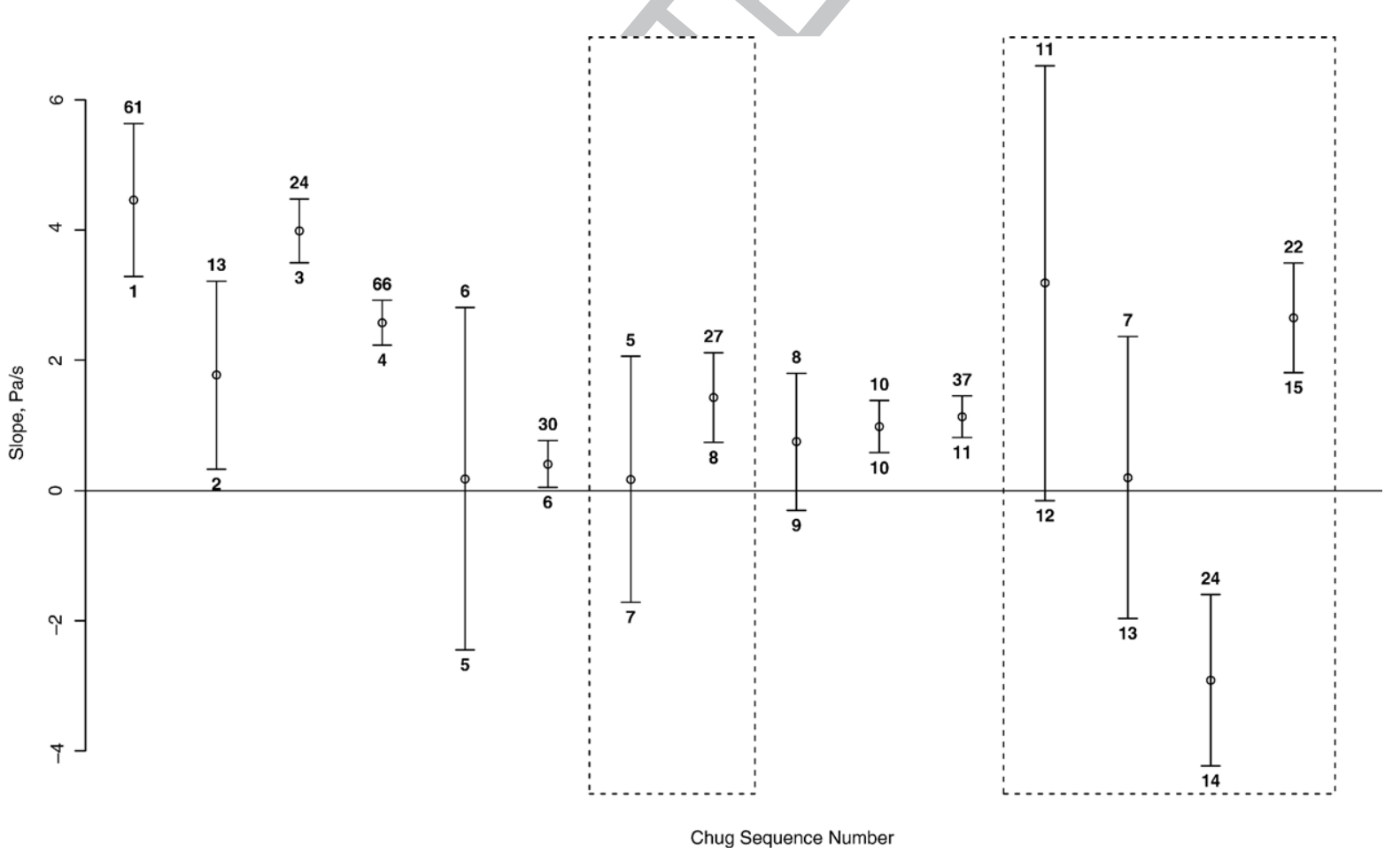

Fig. 4. Summary of regression analyses. Error bars are $95 \%$ confidence bounds formally estimated from linear regression. Each sequence is numbered (lower number) and shows the number of chugs per sequence (upper numeral). Sequence number 4 is presented in Fig. 2. Dashed boxes enclose sequences of intermittent chugging that were broken down into subsets and analyzed individually. The majority of chugging events at Sangay show a positive correlation between pulse interval time and amplitude. 
increasing period for increasing amplitudes (Julian, 1994). Frequency increments of about $100 \%$ over about 10 min have been noted at Sakurajima volcano (Kamo et al., 1977). At Sangay we found that gliding often trends from higher to lower frequencies (Fig. 5), although occasionally chugging sequences appear to have the opposite trend. In some cases, however, gliding shows an increase and later a decrease in frequency over the time span of the sequence. Where chugging is interpreted as a superposition of standing waves, gliding has been viewed as a time varying change in the physical medium (for example, density fluctuations) which produce a drifting of the fundamental frequencies. Benoit and McNutt (1997) attributed frequency variations to changes in the dimensions of magma bodies or gas content. In linear oscillators, damping lowers the natural frequency of oscillation, in non-linear oscillators, damping can also have the opposite effect (Julian, 2000).

It has been established that volcano chugging cannot be modeled by a simple linear system of superposed oscillations (Lees et al., 2004). Since observations at Sangay appear to corroborate the conclusion that the underlying physical mechanism is non-linear, we propose that the observed frequency gliding is related to feedback loops in the vent-gas storage system near the opening of the conduit. As chugging progresses, the aperture where gasses are released undergoes slight modification, coupled with fluctuations of internal pressures within 255 the uppermost conduit. In nearly all cases where there was 256 significant correlation between amplitude and interval 257 time, higher amplitude pulses have longer times. This 258 implies that the mechanism for releasing gasses is related 259 to an increase of pressure associated with a larger volume 260 of gas in the conduit chamber.

We found no correlation between isolated explosion 262 event amplitude (non-chugging or chugging) and lapse 263 time since the previous event. The physical mechanisms 264 that control initial or isolated blasts are most likely dif- 265 ferent from those governing chugging signals. During 266 the 1998 field deployment, initial blasts at Sangay 267 occurred once per hour, on average, producing hundreds 268 of events (over this same period fewer than 20 sequences 269 of chugging were observed, 11 of which are discussed 270 here). All reports of activity from Sangay suggest that 271 this activity has been ongoing since 1628 (Monzier et al., 272 1999). This is in marked contrast to Karymsky where 273 Strombolian activity is intermittent with a decadal cycle 274 that includes vigorous explosion cycles during the active 275 phases. In spite of the differences in physical structure 276 and geologic composition, the two volcano chugging 277 sequences are remarkably similar in frequency content 278 and amplitude range. We speculate that the physical 279 processes governing all chugging signals is a feedback 280 loop controlled by the geometry of the vent opening and 281

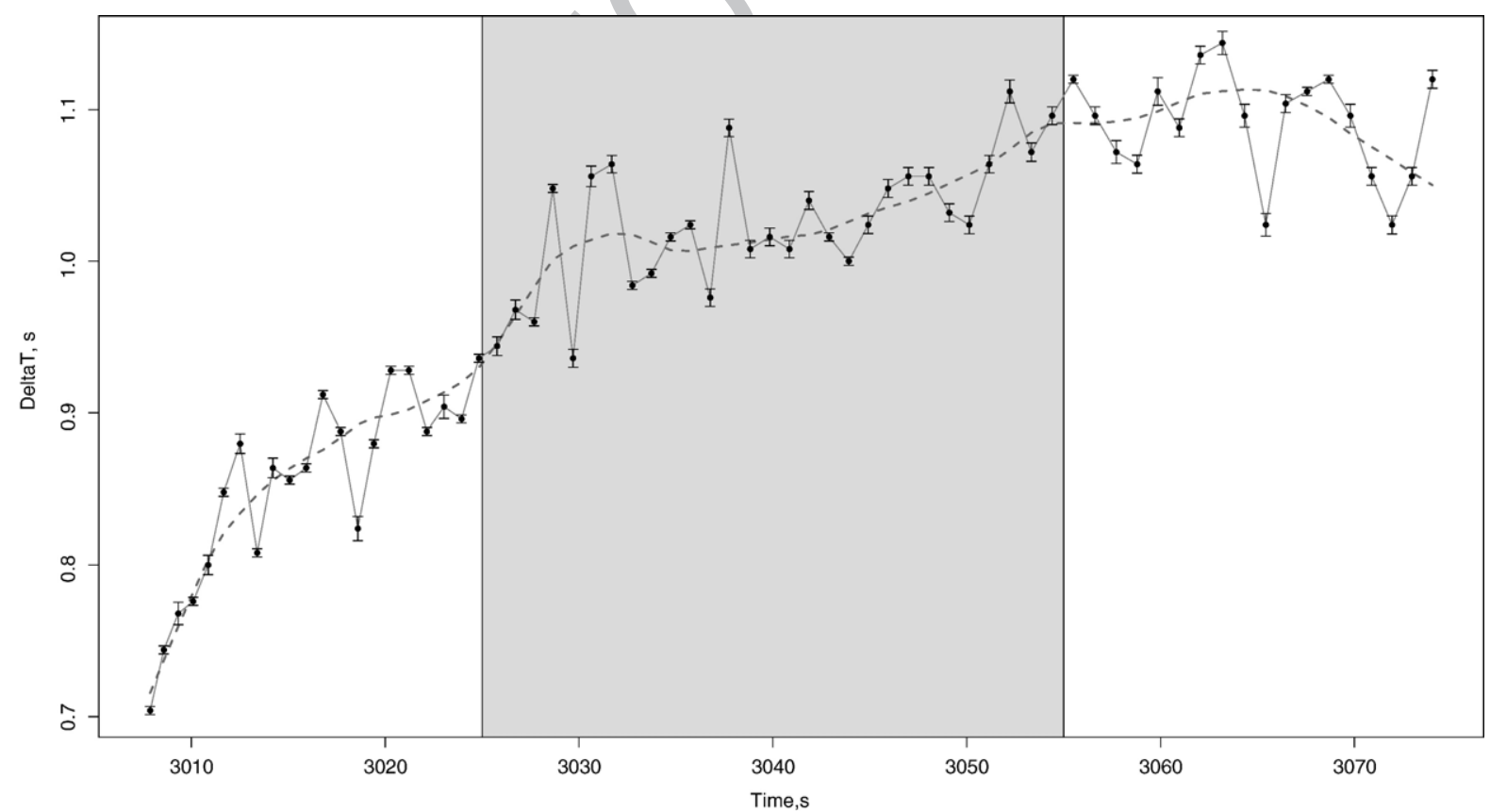

Fig. 5. Gliding interval time between chugs versus time from chugging sequence presented in Fig. 2. In this example the period between chugs increases, so the frequency decreases over the $60 \mathrm{~s}$ span of the chugging event. The shaded region corresponds to time periods discussed in the text where frequencies and particle motion vary. The dashed line is a smoothed representation of the points. Error bars for the timing are estimated as in Fig. 3 . 
the flux of gasses near the surface. For chugging at Karymsky and Sangay volcanoes parameters controlling gas flux appear to be similar. The vent at Karymsky during the times of observation was on the order of tens of meters with debris packing into the crater following each explosion. The aperture extent of the active vent at Sangay in 1998 is unknown because visual observations could not be made at that time. Gliding provides information into the internal dynamics of the conduit physical state and we next invoke powerful processing tools to investigate it further.

\section{Wavelet transforms}

Application of the wavelet transform on the chugging sequence shown above reveals internal temporal variation of the time history of the tremor. In this case we use the Morlet wavelet (Carmona et al., 1998; Addison, 2002; Lees, 2005) as it is appropriate for Ricker type wavelets often observed in seismic records. The mathe- 299 matical form of the Morlet wavelet is a sinusoidal 300 oscillation modulated by a Gaussian window function: 301

$\psi\left(\frac{t-b}{a}\right)=\frac{1}{\pi^{1 / 4}} e^{i 2 \pi f_{0}[(t-b) / a]} e^{-\frac{1}{2}[(t-b) / a]^{2}}$

where $t$ is time, $a$ is a scaling factor, $b$ is shifting pa- 303 rameter, $f_{0}$ is the center frequency for the wavelet, and $i 304$ is the complex number.

305

An example wavelet transform is presented in Fig. 6306 with scale factor 1 and center frequency 5. The Morlet 307 wavelet used in this study is designed so that the first two 308 side lobes of the wavelet are approximately half the 309 amplitude of the central peak (Carmona et al., 1998; 310 Addison, 2002). We present the wavelet transforms of all 311 four recorded signals, three seismic and one infrasound. 312 Details of the wavelet transform of the infrasonic channel 313 from Fig. 6 are presented in Figs. 7 and 8.
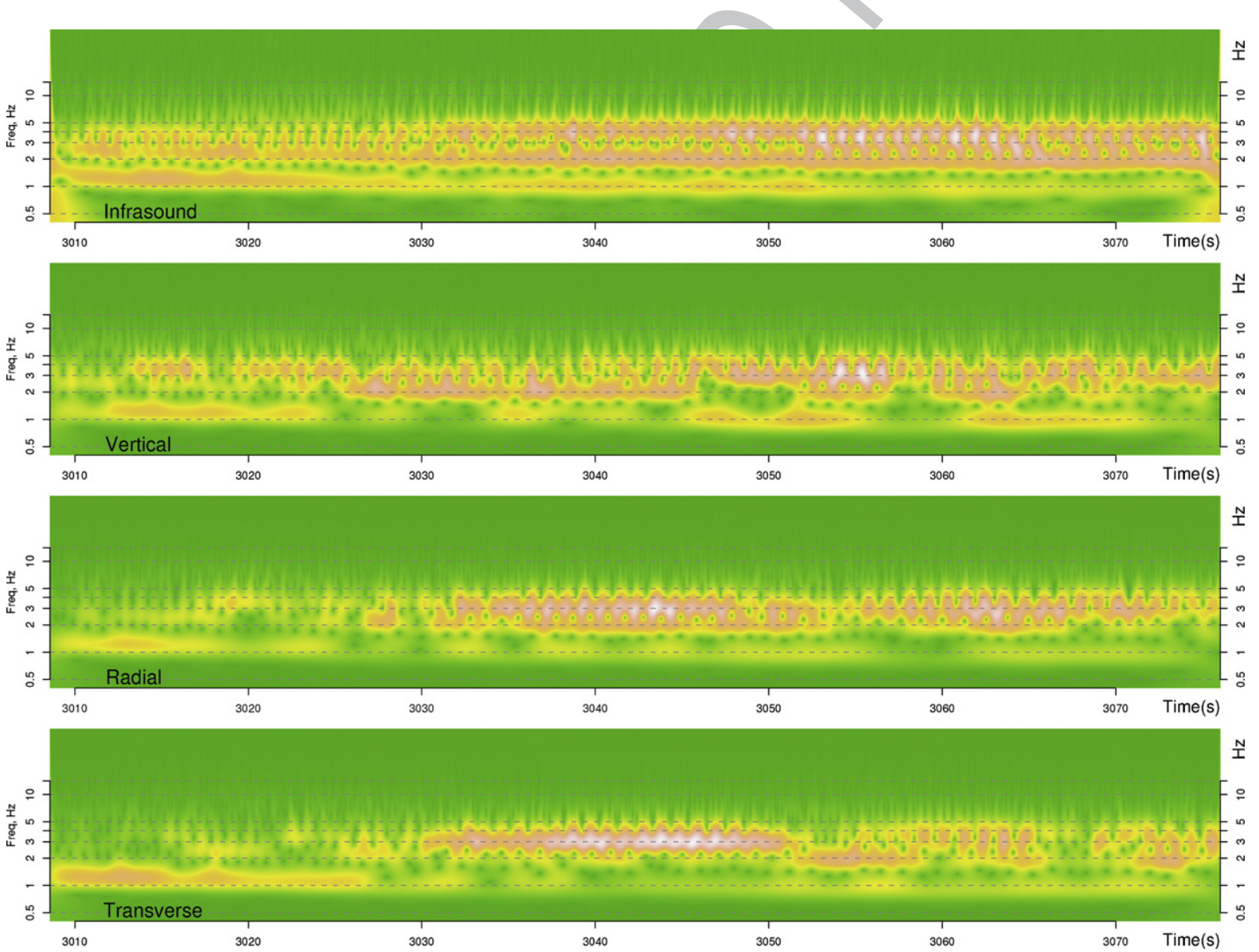

Fig. 6. Wavelet transform of chugging sequence \#4. The figure shows all four channels: one infrasound and three-component seismic. The wavelet transform is designed to accentuate time varying frequency changes during the sequence of chugging tremor. The amplitude of the wavelet transform is based on a cross-correlation and has no units. 


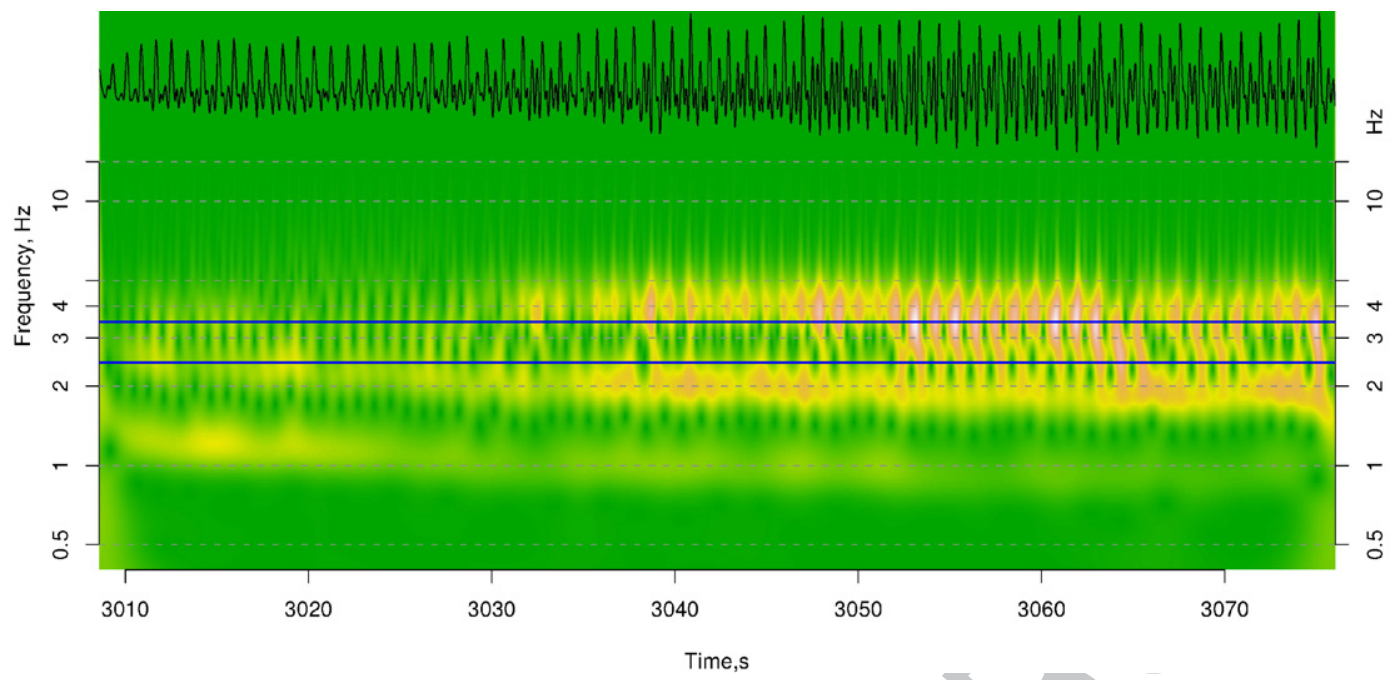

Fig. 7. Detail of wavelet transform of infrasonic component from Fig. 6. Two lines are drawn at frequencies 2.4 and 3.4 to illustrate the frequency-time varying behavior of the vent explosions during a chugging sequence. These rows are extracted in present in Fig. 8.

The wavelet transform can illuminate transient features in the signal that standard spectrograms, commonly used in seismology, do not show. In the example presented in Fig. 7 the wavelet transform accentuates individual pulses and relates information on how these pulses change with time and frequency. By focusing on details of the wavelet transform we can narrow down specific temporal variations in the chugging sequence. Consider two frequencies $3.4 \mathrm{~Hz}$ and $2.4 \mathrm{~Hz}$ in Fig. 7. Near time $3055 \mathrm{~s}$ there appears a slight bifurcation of the frequency content: pulses of $3.4 \mathrm{~Hz}$ are augmented by a 325 series of $2.4 \mathrm{~Hz}$ wavelets. If we extract the rows of the 326 wavelet transform at these frequencies (Fig. 8) the struc- 327 ture become more apparent: around $3055 \mathrm{~s}$ the $2.4 \mathrm{~Hz} 328$ signal is time shifted relative the $3.4 \mathrm{~Hz}$ wave by about 329 $1.3 \mathrm{~s}$, on average. This frequency time shift represents a 330 new input at the source region where the infrasound 331 pulses originate. Prior to 3055 the two frequencies are 332 in phase, and then, rather abruptly, they are tuned out 333 of phase.

334

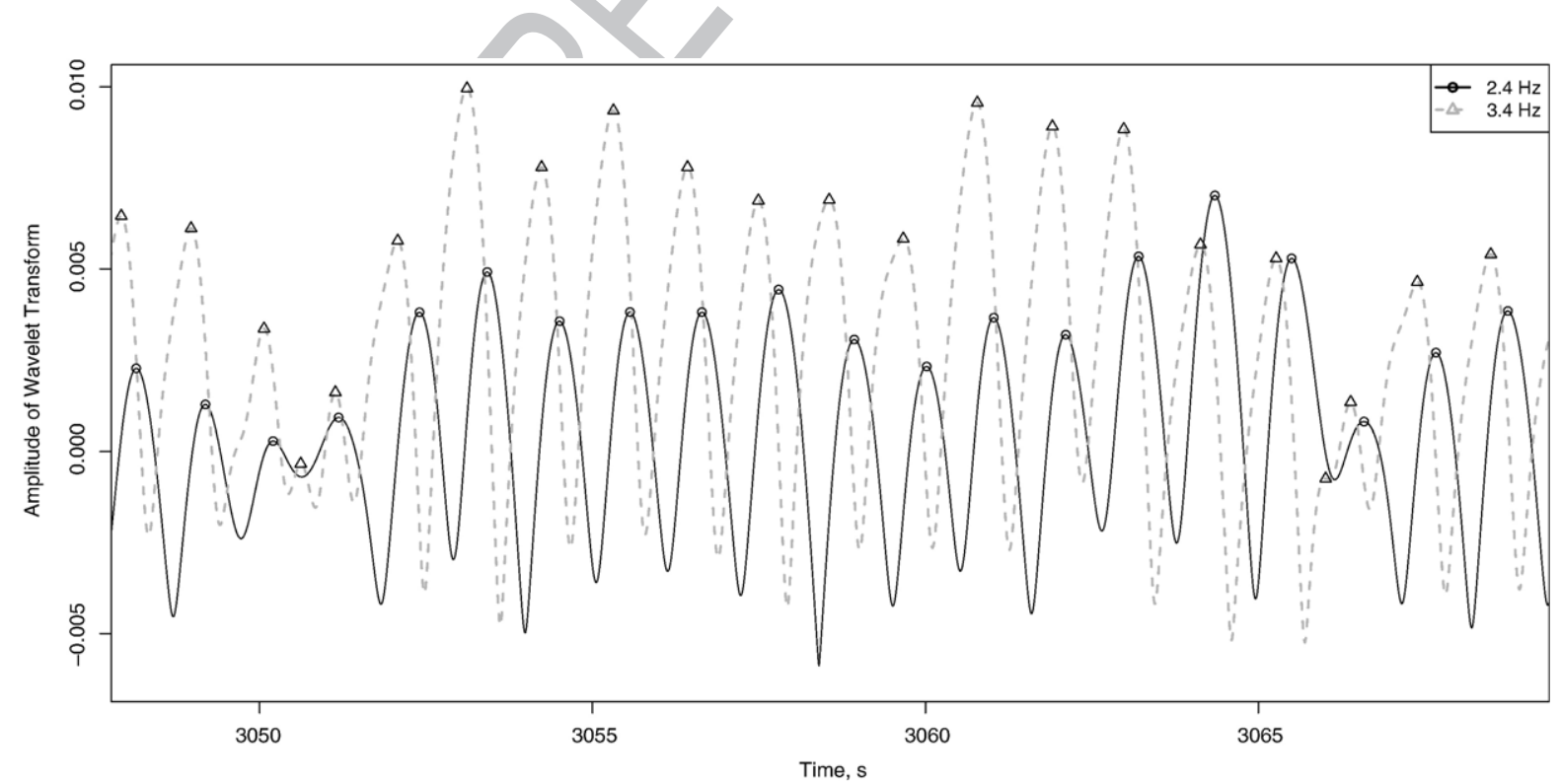

Fig. 8. Two rows of the infrasound wavelet transform extracted from Fig. 7 at 2.4 and $3.4 \mathrm{~Hz}$. The marked peaks are measured in time and an average delay of 1.3 is estimated. 
Analysis of particle motion during chugging sequences is not commonly used, but in this case of chugging it reveals an interesting result. We speculate that particle motion orientation recorded at Sangay in 1998 is most heavily influenced by source effects rather than a path effects, i.e. waves arriving at the station are polarized at the source due to vent characteristics such as geometry, viscosity, or even directional and temporal source variations which produce peculiar radiation patterns.

To analyze temporal variations in chugging particle motion, the three component seismic sequence is broken down into windows of 100 samples long (100/125 s) and eigenvectors of the point clusters for each window are calculated as the window migrates along the trace with $75 \%$ overlap (Fig. 9, see (Lees, 2004) for a description of the methods). Measures of cluster quality are monitored along with the incident angle and azimuth of arrival. In this example (Fig. 9) there is good coherence in the initial part of the chugging sequence, during the first $20 \mathrm{~s}$ (time 3000-3020 s), where the apparent motion of the particles at the seismometer is apparently $90^{\circ}$ rotated from the direction to the vent (Fig. 10). Then, at around $3025 \mathrm{~s} 356$ into the start of the sequence, a higher frequency wave 357 arrives at the station and the particle motion shifts 358 approximately $30^{\circ}$ northward. We note that this effect is 359 accompanied by a slight change in the acoustic signal, 360 but a more significant change occurs at around time 361 $3055 \mathrm{~s}$ where lower frequencies appear to shift as il- 362 lustrated in the previous paragraph (Figs. 7, 8, 9 and 10). 363 It is clear that the dynamics of the chugging sequence 364 varies over the time duration of the tremor, representing 365 possible variations in explosion sources at the vent. The 366 fact that the acoustic record changes in coordination with 367 the seismic particle motion, suggests that particle motion 368 variations originate at the source, since the acoustic 369 waves do not share the same path effects as the seismic 370 waves. A simple model consisting of superposition of 371 standing waves in a column of rising magma or in a 372 relatively shallow, mixed-phase conduit cannot explain 373 these variations in behavior without invoking changes of 374 the conduit geometry and/or physical characteristics 375 over time periods of seconds or fractions thereof. On the 376
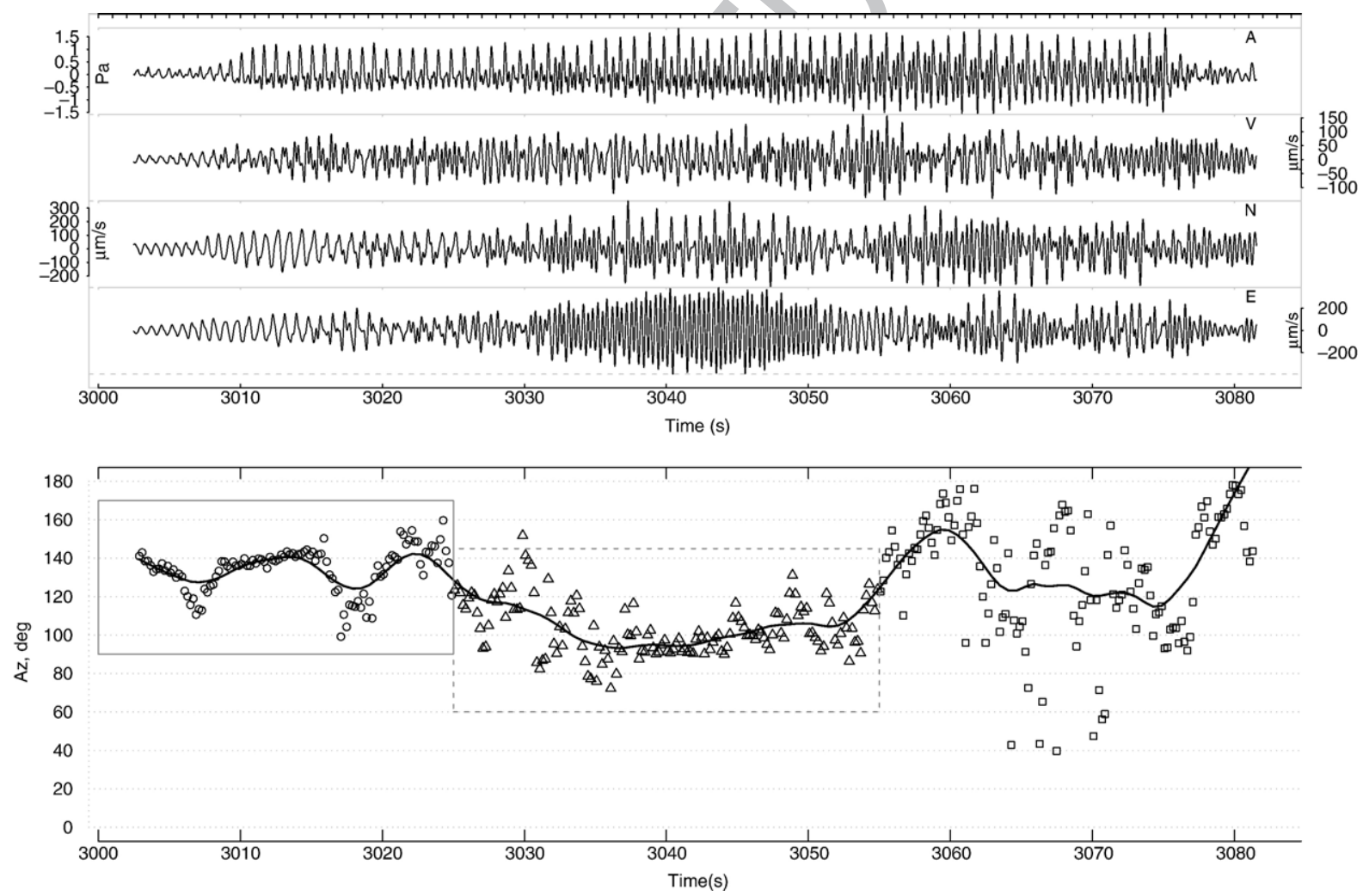

Fig. 9. Particle motion of chugging sequence. The upper panel shows the infrasound and the three components of the particle motion. The lower panel shows the azimuthal direction of particle motion estimated over moving windows of 100 samples (sample rate $=0.008 \mathrm{~s}$ ) with $75 \%$ overlap. The directions are derived from eigenvalue decomposition of velocity vectors, followed by projection onto the horizontal plane. The left box (3000-3025 $\mathrm{s}$, circles) exhibits a significantly different orientation of particle motion than the central box. The central box (3025-3055 s, triangles) corresponds to the zone where the frequencies are shifting as described by the infrasound wavelet analysis. 


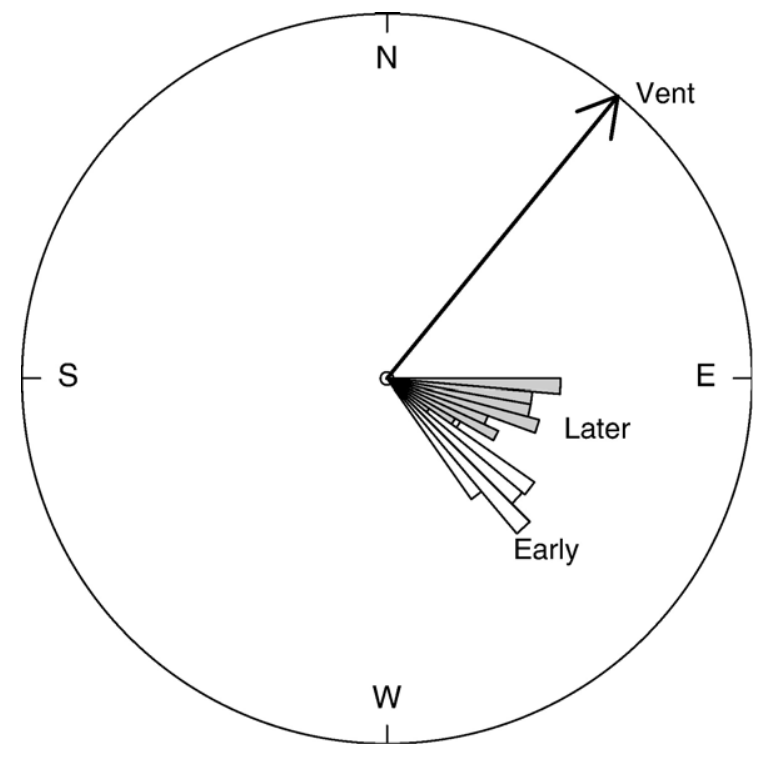

Fig. 10. Azimuthal distribution of particle motion relative to the vent direction. The "early" (white) period corresponds to time span 3000$3025 \mathrm{~s}$ (circles) in Fig. 9, the "later" (grey) period corresponds to time $3025-3055 \mathrm{~s}$ (triangles). A slight shift northward is seen in the orientation of the chugging signals over time corresponding to a change in explosion source orientation.

other hand if the extrusion of gases changes directions because of adjustments at the vent during the course of a chugging sequence, we may speculate that the shear waves arriving at the station rotate their orientation, producing the observed polarization shift.

\section{Discussion}

Lees et al. (2004) found a strong, apparently linear, correlation between chugging time intervals and corresponding signal amplitudes at Karymsky Volcano. Visual observations of Karymsky Volcano explosions in 1997/ 1998 suggest that, during chugging activity, Karymsky produced gas/ash explosions from a single eruption vent at the summit. The lone vent acted as the sole source of infrasonic activity, both for chugging and non-chugging events. Video recordings of explosions at Karymsky in 1998 showed that at least two, distinct and separate plumes were evident during explosions (Johnson, in press). The plumes appeared to emanate from the same vent nearly simultaneously; a smaller, lighter colored cloud along with a darker, much larger plume of ash, pyroclastics and debris. We presume that the smaller, white plume consisted primarily of water vapor. During the 1998 deployment at Sangay, only one vent was observed and the presence or absence of multiple plumes is unknown.
Using a new technique in the time domain, a statis- 402 tically significant positive correlation between time delays 403 and pressure amplitudes of chugging events was found on 404 Sangay's infrasound data. This fact shows that chugging 405 events at Karymsky and Sangay have more similarities 406 than previously was noticed. The fact that amplitudes 407 appear to be correlated with time intervals between chugs 408 is significant. It suggests that it is highly unlikely that the 409 process governing the chugging phenomenon can be 410 modeled as a (simple, linear) superposition of waves in 411 the conduit. This observation cannot be easily deduced 412 from standard spectral analysis of the chugging se- 413 quences. Frequency gliding has been observed at Arenal 414 volcano, although the relation of amplitude to pulse 415 frequency was not readily observed until it was noted at 416 Karymsky (Lees et al., 2004). In this study we introduce 417 the wavelet analysis to probe the time-frequency relation 418 of the chugging sequences because standard spectrogram 419 analysis smears information in time. The wavelet analysis 420 has better time resolving power than traditional spectro- 421 grams and thus shows details of frequency evolution. 422 During the sequence where frequency splitting and abrupt 423 changes occur over time spans of seconds (or less) the 424 wavelet transform provides insight into time variations of 425 the volcanic explosion source.

Konstantinou and Lin (2004) found that chugging 427 signals from Sangay have a low correlation dimension 428 $(1.8-2.4)$ and a Lyapunov exponent in the range of 429 $0.013-0.022$. From these results, they inferred that 430 chugging events can be modeled by non-linear processes 431 (positive Lyapunov exponent) with a low number of 432 degrees of freedom given by a small fractal dimension. 433 Theoretical process mechanisms can be generated by 434 simple sets of non-linear, differential equations such as 435 the Van der Pol or Duffing equations (Julian, 2000; 436 Konstantinou and Schlindwein, 2003). While these 437 equations retain some of the very gross characteristics 438 of the tremor observed we have found simulations based 439 on these simple assumptions seriously lacking.

A variety of non-linear, physical models have been 441 postulated for harmonic tremor on Strombolian style 442 explosive volcanoes, including: a) fluid flow through 443 cracks (Julian, 1994, 2000); b) pressure cooker model 444 (Lees and Bolton, 1998); and c) generation of Von 445 Karman vortices related to obstructions in a conduit 446 (Hellweg, 1999, 2000) and crack vibrations (Chouet, 447 1986, 1988; Chouet et al., 2003). For now, we cannot 448 speculate on the appropriateness of such models for 449 illuminating the observations reported here, although it 450 should be noted that it is possible to design sets of 451 differential equations that produce sequences of signals 452 similar to those discussed here. Lees and Bolton (1998) 453 
proposed a set of non-linear differential equations relating choked flow with feedback mechanisms, although these models are still being explored to determine the best parameter estimates and their relation to physical volcanoes. Details of time series produced by these sequences of pulsations will have to be recorded with high fidelity at numerous stations before we can formulate reliable inverse procedures to determine the underlying physical processes. Furthermore, it is most probable that non-uniqueness of parameters sets defining small sets of differential equations proposed to simulate these phenomena will preclude a single, geologically significant, solution. Cross-disciplinary observations (thermal, visual, chemical, etc...) may offer hope to narrow model space of parameter sets that potentially satisfy the seismo-acoustic data, and some efforts along these lines are currently being investigated, although concrete results are not available as yet (Harris et al., 2003; Neuberg, 2006).

The correlation of particle motion variations and infrasonic frequency shifting suggests that the underlying geometry of the source is changing over the time span of one chugging event. At this point we do not have enough constraints to determine if changes in the source occur at depth (tens to hundreds of meters) or at the surface where the infrasound is generated. We speculate that it is unlikely that the variations observed here are produced by deep sources in the vent. Rather we suggest that perturbations shown above most probably result from rapid modifications of the near surface vent during the evolution of the chugging sequence. The modification maybe a slight opening or closing of the aperture or ablation of the edges of the vent which drives the frequency modulation and longer term gliding. A simple feedback mechanism that controls the pressure in the near surface conduit and the aperture of the vent can provide the necessary non-linear behavior required by the amplitude/repose time phenomena shown in Fig. 5. This model has been proposed by others (Johnson et al., 1998; Lees et al., 2004), although a strict mathematical formulation has not been worked out formally (Lees and Bolton, 1998).

\section{Conclusions}

By working in the time domain to estimate arrival times of pulses during tremor events we have reduced the error and increased the precision of time-amplitude observations of explosions at Sangay and Karymsky volcanoes. Sangay volcano exhibits quasi-periodic sequences of pulses following explosions which are known as chugging. Numerous sequences were analyzed and shown to have a statistically significant positive correla- 504 tion between amplitude and interval repose time. The 505 strong correlation between pulse amplitude and repose 506 time interval suggests feedback mechanisms and chaotic 507 behavior similar to other volcanological phenomena 508 where fluids are assumed to flow through narrow conduits 509 and excite non-linear oscillatory vibration. The close 510 association of particle motion variations and frequency- 511 phase shifts estimated from wavelet transforms indicates 512 modifications of the source/vent geometry rather than a 513 deep seated variation. At the interface between the vol- 514 cano and the atmosphere this phenomena leads to audible 515 chugging that is prominent in the infrasonic bandwidth 516 $(0.7-2 \mathrm{~Hz})$ and can be modeled as choked flow from a 517 relatively shallow conduit chamber.

\section{Acknowledgments}

The authors thank Jeff Johnson for his help in col- 520 lecting data at Sangay, and the IRIS PASSCAL instrument 521 center for providing hardware and logistical support. This 522 paper is dedicated to the memory of our friend Diego 523 Viracucha who participated in the field deployment. The 524 authors thank Vera Schlindwein, editor Jeff Johnson, and 525 an anonymous referee for constructive reviews. Support 526 for this work was provided by grants NSF EAR 0337462527 and NSF: EAR-9614639.

\section{References}

Addison, P.S., 2002. The Illustrated Wavelet Transform Handbook: 530 Introductory Theory and Applications in Science, Engineering, 531 Medicine and Finance. Institute of Physics Publishing, Bristol. 353 pp. 532

Benoit, J.P., McNutt, S.R., 1997. New constraints on source processes 533 of volcanic tremor at Arenal Volcano, Costa Rica, using broadband 534 seismic data. Geophys. Res. Lett. 24 (4), 449-452. 535

Carmona, R., Hwang, W.-L., Torresani, B., 1998. Practical Time- 536 Frequency Analysis: Gabor \& Wavelet Transforms with an 537 Implementation in S. Academic Press. 490 pp.

Chouet, B., 1986. Dynamics of a fluid-driven crack in three dimensions 539 by the finite difference method. J. Geophys. Res. 91, 13,967-13,992. 540

Chouet, B., 1988. Resonance of a fluid-driven crack: radiation 541 properties and implications for a source of long-period events 542 and harmonic tremor. J. Geophys. Res. 93, 4375-4400. 543

Chouet, B., et al., 2003. Source mechanisms of explosions at Stromboli 544 Volcano, Italy, determined from moment-tensor inversions of very- 545 long-period data. J. Geophys. Res. 2019. doi:10.1029/2002JB001919. 546

Eichelberger, J.C., Izbekov, P.E., 2000. Eruption of andesite triggered 547 by dyke injection: contrasting cases at Karymsky Volcano, 548 Kamchatka and Mt. Katmai, Alaska. Philos. Trans. R. Soc. Lond. 549 358, 1465-1485.

Garces, M.A., Hagerty, M.T., Schwartz, S.Y., 1998. Magma acoustics 551 and time-varying melt properties at Arenal Volcano, Costa Rica. 552 Geophys. Res. Lett. 25 (13), 2293-2296.

Hagerty, M.T., Schwartz, S.Y., Garces, M.A., Protti, M., 2000. 554 Analysis of seismic and acoustic observations at Arenal Volcano, 555 
Costa Rica, 1995-1997. J. Volcanol. Geotherm. Res. 101 (1-2), 27-65.

Harris, A., et al., 2003. Ground-based infrared monitoring provides new tool for remote tracking of volcanic activity. Eos, Trans. - Am. Geophys. Union 84 (40), 409-418.

Hellweg, M., 1999. Listening carefully: unique observations of harmonic tremor at Lascar volcano, Chile. Annali di Geofisica 42, 451-464.

Hellweg, M., 2000. Physical models for the source of Lascar's harmonic tremor. J. Volcanol. Geotherm. Res. 101 (1-2), 183-198.

Johnson, J.B., in press. On the relation between, infrasound, seismicity, and small pyroclastic explosions at Karymsky Volcano. J. Geophys. Res.

Johnson, J.B., Lees, J.M., 2000. Plugs and chugs — Strombolian activity at Karymsky, Russia, and Sangay, Ecuador. J. Volcanol. Geotherm. Res. 101, 67-82.

Johnson, J.B., Lees, J.M., Gordeev, E., 1998. Degassing explosions at Karymsky Volcano, Kamchatka. Geophys. Res. Lett. 25 (21), 3999-4042.

Johnson, J.B., et al., 2003. Interpretation and utility of infrasonic records from erupting volcanoes. J. Volcanol. Geotherm. Res. 121 (1-2), 15-63.

Julian, B.R., 1994. Volcanic tremor: nonlinear excitation by fluid flow. J. Geophys. Res. 99 (B6), 11859-11877.

Julian, B.R., 2000. Period doubling and other nonlinear phenomena in volcanic earthquakes and tremor. J. Volcanol. Geotherm. Res. 101 (1-2), 19-26.

Kamo, K., Furuzawa, T., Akamatsu, J., 1977. Some natures of volcanic micro-tremors at the Skaura-jima volcano. Bull. Vocanol. Soc. Jpn. 22, 41-58.

Konstantinou, K.I., Schlindwein, V., 2003. Nature, wavefield properties and source mechanism of volcanic tremor; a review. J. Volcanol. Geotherm. Res. 119 (1-4), 161-187.
Konstantinou, K.I., Lin, C.H., 2004. Nonlinear time series analysis of 589 volcanic tremor events recorded at Sangay volcano, Ecuador. Pure 590 Appl. Geophys. 161 (1), 145-163.

Lees, J.M., 2004. Scattering from a fault interface in the Coso 592 geothermal field. J. Volcanol. Geotherm. Res. 130 (1-2), 61-75. 593

Lees, J.M., 2005. Wavelet transforms and volcanic explosions. Eos, 594 Trans. AGU, p. S31C-03. Fall Meet. Suppl.

Lees, J.M., Bolton, E.W., 1998. Pressure Cookers as Volcano Analogues. 596 Eos, Trans. AGU, p. 620.

Lees, J.M., Gordeev, E.I., Ripepe, M., 2004. Explosions and periodic 598 tremor at Karymsky Volcano, Kamchatka, Russia. Geophys. J. Int. 599 0 (0). doi:10.1111/j.1365-246X.2004.02239.x.

600

Monzier, M., et al., 1999. Sangay Volcano, Ecuador; structural 601 development, present activity and petrology. J. Volcanol. Geotherm. 602 Res. 90 (1-2), 49-79.

603

Mori, J., et al., 1989. Seismicity associated with eruptive activity at 604 Langila volcano, Papau New Guinea. J. Volcanol. Geotherm. Res. 605 $38,243-255$.

Neuberg, J.W., 2006. Multi-parameter monitoring and modelling of 607 volcanic processes. In: Mader, H.M., Coles, S.G., Connor, C.B. 608 (Eds.), Statistics in Volcanology. Special Publications of IAVCEI. 609 Geological Society, London, pp. 215-230.

Ozerov, A., Ispolatov, I., Lees, J., 2003. Modeling Strombolian eruptions 611 of Karymsky volcano, Kamchatka, Russia. J. Volcanol. Geotherm. 612 Res. 122 (3-4), 265-280.

R Development Core Team, 2006. R: A Language and Environment for 614 Statistical Computing. In: R.F.f.S.Computing (Ed.), Vienna, Austria. 615

Zobin, V.M., Levina, V.I., 1998. Rupture history of the January 1, 616 1996, Ms 6.6 volcanic earthquake preceding the simultaneous 617 eruption of Karymsky and Akademia Nauk volcanoes in 618 Kamchatka, Russia. J. Geophys. Res. 103 (8), 18,315-18,324. 619 